Regards sur l'économie allemande

Bulletin économique du CIRAC

$83 \mid 2007$

Varia

\title{
Décryptage : Pouvoir d'achat et salaires nets stagnent depuis 20 ans ?!
}

\section{Isabelle Bourgeois}

\section{(2) OpenEdition}

1 Journals

Édition électronique

URL : http://journals.openedition.org/rea/599

DOI : 10.4000/rea.599

ISBN : 978-2-8218-0862-1

ISSN : 1965-0787

\section{Éditeur}

CIRAC

Édition imprimée

Date de publication : 1 octobre 2007

Pagination : 37

ISSN : 1156-8992

Référence électronique

Isabelle Bourgeois, « Décryptage : Pouvoir d'achat et salaires nets stagnent depuis 20 ans ?! », Regards sur l'économie allemande [En ligne], 83 | octobre 2007, document 1, mis en ligne le 01 octobre 2009, consulté le 15 septembre 2020. URL : http://journals.openedition.org/rea/599

Ce document a été généré automatiquement le 15 septembre 2020.

(c) CIRAC 


\title{
Décryptage : Pouvoir d'achat et salaires nets stagnent depuis 20 ans ?!
}

\author{
Isabelle Bourgeois
}

1 Des statistiques issues du ministère fédéral $d u$ Travail ont récemment défrayé la chronique bien au-delà du Rhin. Selon ces données que le quotidien à fort tirage BILD a propulsées en tête de l'agenda, le pouvoir d'achat des Allemands aurait stagné en 20 ans. Les salariés n'auraient pas pu profiter des fruits de la croissance. La faute à une modération salariale unique en Europe, à des prélèvements à la dérive, à l'inflation? Les coupables sont vite identifiés, et ils pullulent d'autant plus facilement qu'on additionne des choux et des carottes. A commencer par la période retenue. Comparer les salaires mensuels nets des années 1986 et 2006 (respectivement $1315,4 €$ et $1320,4 €$ ) n'a pas de sens : la moyenne d'il y a 20 ans ne se rapporte qu'à la RFA d'avant l'Unité - donc aux seuls 11 Länder de l'ouest. Aucune conclusion ne peut être tirée de la mise en relation de ces données. Les comparaisons ne prennent de sens qu'à partir de l'Unité, c'est-à-dire de l'année 1991. Et si on regarde les chiffres publiés par le ministère, le salaire net réel mensuel des Allemands est passé de $1141 €$ en 1991 à $1454 €$ en 2006.

2 On pourrait citer une multitude d'autres chiffres, au demeurant tous accessibles au public puisque le ministère fédéral du Travail les diffuse depuis 40 ans sous forme de livre de poche et, depuis l'ère numérique, parallèlement sur son site Internet (www.bmas.de). Quoi qu'on cherche à leur faire dire, il s'agit de moyennes, donc de données purement statistiques, et qui n'ont de surcroît aucune valeur pour évaluer le pouvoir d'achat tant qu'elles ne sont pas replacées dans le contexte de la totalité des revenus (fiscalité, transferts, etc.) et considérées sous l'angle des mutations du travail. Pour évaluer le poids des prélèvements sur le salaire, même moyen, il faudrait diversifier par type d'emploi ou de branche, pour évaluer les transferts, tenir compte de la situation familiale, etc. Certes, cotisations et fiscalité sont élevées en Allemagne, 
représentant au fil des années écoulées tantôt un peu plus, tantôt un peu moins de 40 \% du salaire brut.

3 Mais le plus important n'est pas là. La relative stagnation des salaires, bien réelle, et prise globalement, traduit surtout les mutations de l'emploi. Elle reflète une baisse de $8 \%$ de la durée du temps de travail depuis 1991, sous l'effet de négociations conventionnelles et plus encore de la diffusion du temps partiel. Elle reflète de même la hausse des petits boulots (mini-jobs et autres) dont on dénombre aujourd'hui quelque 2 millions. Ensuite, la répartition des emplois par secteurs a évolué, les meilleurs salaires étant versés dans l'industrie, le commerce ou la banque et l'assurance - le corollaire de la montée du temps partiel et du travail précaire dans les autres services. La part des travailleurs indépendants est en forte croissance, etc.

4 Ce qui est significatif, c'est plutôt l'usage partisan qui est fait actuellement de ces données laissant entendre une stagnation du pouvoir d'achat. Elle est imputable au poids des prélèvements? Raison de plus, surtout en période d'assainissement budgétaire, de les ramener à de plus justes proportions, répètent les fédérations patronales. Elle est le fait d'entreprises âpres au gain et qui, bien que profitables, refusent de partager avec les salariés? Raison de plus pour revendiquer des hausses salariales en proportion, s'écrient certains syndicats. Surtout pas, rétorque le gouvernement fédéral, la modération salariale a été et est toujours l'un des pivots de la compétitivité retrouvée ! Cette stagnation révèle l'importance croissante du groupe des working poor généré par la tertiarisation, la libéralisation des services publics, voire la montée en puissance de l'intérim ? Raison de plus pour introduire un salaire minimum légal, expliquent un certain nombre de syndicats et toute la gauche allemande, y compris la gauche du SPD, mais aussi une partie des chrétiens-démocrates... Alors que se tiennent des négociations conventionnelles importantes, que SPD et CDU/CSU refondent leur programme et que se profilent nombre d'échéances électorales, les données statistiques se révèlent visiblement des outils précieux dans le 'débat', en Allemagne comme ailleurs.

INDEX

Mots-clés : conjoncture, pouvoir d'achat, salaire 